Wilfrid Laurier University

Scholars Commons @ Laurier

\title{
Moral Identity as a Goal of Moral Action: A Self-Determination Theory Perspective
}

Tobias Krettenauer

Wilfrid Laurier University, tkrettenauer@wlu.ca

Follow this and additional works at: https://scholars.wlu.ca/psyc_faculty

Part of the Developmental Psychology Commons

\section{Recommended Citation}

Krettenauer, T. (2020). Moral Identity as a goal of moral action: A Self-Determination Theory perspective. Journal of Moral Education, 49, 330-345. https://doi.org/10.1080/03057240.2019.1698414

This Article is brought to you for free and open access by the Psychology at Scholars Commons @ Laurier. It has been accepted for inclusion in Psychology Faculty Publications by an authorized administrator of Scholars Commons@Laurier. For more information, please contact scholarscommons@wlu.ca. 
Running head: MORAL IDENTITY AS A GOAL

Moral Identity as a Goal of Moral Action: A Self-Determination Theory Perspective Tobias Krettenauer

Krettenauer, T. (2020). Moral Identity as a goal of moral action: A Self-Determination Theory perspective. Journal of Moral Education, 49, 330-345.

https://doi.org/10.1080/03057240.2019.1698414

Author Note

Tobias Krettenauer, Department of Psychology, Wilfrid Laurier University, Waterloo, Canada.

A preliminary version of this paper was presented at the Self-Determination Theory Conference 2019, Amsterdam, May 21-24, 2019.

Please address correspondence concerning this article to: Tobias Krettenauer, Department of Psychology, Wilfrid Laurier University, 75 University Ave W, Waterloo, Ontario, N2L 3C5, Canada; email: tkrettenauer@wlu.ca. 


\begin{abstract}
This paper aims at connecting Self-Determination Theory (SDT) with research on moral identity. It is argued that SDT provides a unique and integrative framework for addressing important questions that have guided research on moral identity for many years: What is a moral identity? How is it linked to moral action? How do moral identities develop? In the present paper, moral identity is conceptualized as a goal of moral action. Individuals want to maintain their moral identity, which in turn motivates them to act morally. Yet, moral identity motivation is not uniform. In line with SDT, it is possible to differentiate between more or less external and internal forms of moral identity motivation. The exact link between moral identity and moral action depends on the type of moral identity motivation involved. Development of moral identity trends towards more internal forms of moral identity motivation, which renders development an influential factor in shaping individuals' motivation to act morally. Key words: moral identity, Self-Determination Theory, moral motivation, moral development
\end{abstract}


Moral Identity as a Goal of Moral Action: A Self-Determination Theory Perspective What is a moral identity? How is it linked to moral action? How do moral identities develop? These questions are central to the field of moral identity research. They have been discussed numerous times in several comprehensive reviews (e.g., Hardy \& Carlo, 2005, 2011; Hardy, Krettenauer, \& Hunt, in press; Jennings, Mitchell, \& Hannah, 2015). Typically, two major approaches to moral identity are identified and contrasted, "trait-based" versus "socio-cognitive" approaches. From a trait-based perspective, moral identity is a trait-like personality attribute that manifests in stable behavioural dispositions to act morally across contexts and time. From a socio-cognitive perspective, moral identity is a malleable self-schema that needs to be activated in a given situation to influence social information processing, decision-making and behavior. While these two major approaches capture most of the research in this field, they do not exhaust all theoretical options available. Walker (2014) for instance, introduced the socalled personological approach to moral identity, while Stets and Carter (2012) provide a sociological account. However, even when considering the full range of theoretical offerings, Self-Determination Theory (SDT) as proposed by Edward Deci and Richard Ryan (e.g., Deci \& Ryan, 2012; Ryan \& Deci, 2018) is not among them. While some connections were drawn in the past between SDT and ego identity from an Eriksonian perspective (Soenens \& Vansteenkiste, 2011), SDT has not been a serious contender in the field of moral identity research so far. This is puzzling as this theory tackles questions very similar to those faced by moral identity researchers: What motivates individuals to act? How is the self implicated in this motivation? How does motivation change over time as individuals experience various forms of feedback for their actions? 
This paper is meant to bridge the gap between SDT and moral identity research. It is based on the assumption that SDT can greatly inform moral identity research as it provides a unique perspective on central questions that have been guiding this field of research for a long time. In brief, the following answers will be given to the three guiding questions cited above: (1) What is a moral identity? - Moral identity can be considered a goal of moral action. Individuals want to maintain their moral identity, which in turn motivates them to act morally. Note that this conceptualization of moral identity does not directly follow from a SDT perspective. Yet, as will be argued below, SDT suggests such a view. (2) How is moral identity linked to moral action? - Moral identity motivation is not uniform. In line with SDT, it is possible to differentiate between more or less external and internal forms of moral identity motivation. The exact link between moral identity and moral action depends on the type of moral identity motivation involved. (3) How does moral identity develop? - Development of moral identity trends towards more internal forms of moral identity motivation, which renders development an influential factor in shaping individuals' moral motivation.

In the following sections these propositions will be further elaborated and substantiated. For doing so, we will draw from various areas of research across the broad field of moral psychology. We will rely on important conceptual distinctions and wellestablished empirical findings, some from our own research projects. Thus, the present paper weaves together various lines of arguments in order in order to drive home one major point: SDT provides an integrative perspective for addressing questions moral identity researchers have been grappling with since Blasi introduced the concept in the 
1980s (Blasi, 1983; 1984). This perspective opens up promising avenues for new research and broadens the scope of moral identity research.

\section{Moral identity as a goal of moral action}

Moral identity is commonly defined as "the degree to which being a moral person is important to an individual's identity" (Hardy \& Carlo, 2005, p. 212). While this definition captures the subjective experience of having a moral identity, it does not explicate moral identity as a psychological construct. What is moral identity from the perspective of psychological theory? It has been argued that moral identity can be conceptualized on various levels of abstraction that are all pertinent for describing the moral person (Krettenauer \& Hertz, 2015). Following McAdams' framework of personality (e.g., McAdams, 2015), moral identity can be conceptualized (a) as a traitlike attribute, (b) as a context-specific adaptation and goal-orientation, and (c) as a narrative. On the broadest, most abstract, and least contextualized level, moral identity consists of those moral qualities individuals ascribe as important to themselves in general (e.g., being honest, responsible, principled, etc.). On an intermediate level, moral identities are represented by different goal-orientations individuals maintain in various areas of their life (e.g., being a caring parent and a fair-minded colleague). On the least abstract level, moral identities are expressed in life stories about moral achievements and failures in people's lives. These life stories mitigate discrepancies and inconsistencies among conflicting self-aspects (McAdams, 1993) and sustain a personal sense of moral agency (Pasupathi \& Wainryb, 2010). Evidently, the intermediate level of contextspecific adaptations and goal-orientations is most akin to SDT as context-dependent personal goals play a pivotal role in this theory. Thus, from a SDT perspective moral 
identity is best conceptualized as a goal of moral action within McAdams' framework of personality. Individuals act morally in order to uphold their moral identity. Put differently, moral actions are instrumental for moral identity maintenance. This statement may sound straightforward. It nonetheless requires further explanation and elaboration.

The philosophically minded reader may find the conceptualization of moral identity as a goal of moral action highly implausible as it appears to deny what it wants to explain: moral action. An action needs to be motivated by the desire to do what is considered morally right or good in order to qualify as moral (Blasi, 2005). If the goal simply is to bolster one's sense of self, the action appears to be devoid of any moral meaning. Ethical egoism seems to be logically implied (Nucci, 2004). However, this is not the case. Any human action is part of a chain of proximal desires or intentions and more distal goals that often form goal hierarchies (Austin \& Vancouver, 1996). For instance, someone regularly walks or bikes to the office in the morning because they want to use the car less often. Using the car less, in turn, is motivated by the desire to reduce one's carbon footprint and to develop a more sustainable life-style. In a similar way, any honest, caring or fairness behavior can be motivated by the desire to do what is considered morally right or good and by the goal to maintain one's moral identity. One goal does not come at the expense of the other. Instead both can support each other. Moral identity as a goal adds another motive for moral action to the desire to do what is good or right (see Hardy, 2006). As a consequence, the motivation to act morally overall might become stronger, more reliable and more robust once it is backed by a moral identity. 
It is important to note, however, that the criteria for successful identity maintenance can vary. They can be rather externally defined by the acknowledgement and recognition individuals receive from others, or they can be internally defined by the personal confirmation of one's own self-view. Consequently, a moral identity can be associated with different motivations. Individuals may want to be recognized by others as respected members of their moral community (see Ellemers, Pagliaro, \& Barreto, 2013). Alternatively, individuals may seek confirmation of their own self-view as a form of selfconsistency or -coherence (see Lapsley \& Stey, 2014).

Last but not least, moral identity as a goal does not always necessitate moral action. If action is instrumental for achieving the goal of moral identity maintenance, there might be other means for achieving this goal that are equally effective. Individuals may deny the moral significance of an action by using various strategies of moral disengagement (Bandura, 2016). They may, for instance, minimize the negative consequences of an action for others or deny their own responsibility to act. As a consequence, one's moral identity remains unaffected by whatever course of action is taken in a given situation. Even if such measures of moral disengagement are not available, individuals are not bound to act morally. Instead, they may choose to act immorally as they believe that they will be able to make up for any moral identity loss at a later point in time. Thus, moral identity maintenance is not static but a dynamic process that unfolds over extended periods of time. It is a balance individuals constantly seek to maintain as they pursue various goals in life, may they be moral, amoral, or immoral (see Mazar, Amir, \& Ariely, 2008). 
Social-psychological research on moral balancing illustrates this view. This research demonstrates that past behavior influences individuals' readiness to engage in future moral action, depending on what self-image it invokes. If past behaviors question one's self-view as a moral person the readiness to engage in future prosocial or moral action tends to increase. If the past behavior confirms one's moral identity, people are more willing to excuse themselves when failing to act morally. This effect has been called moral licensing (Sachdeva, Iliev, \& Medin, 2009). Moral licensing occurs across domains, for instance when volunteering for a charity organization leads to smaller monetary donations for other charitable causes (Blanken, Van de Ven, \& Zeelenberg, 2015). Licensing effects are replicable and reliable, albeit small (Mullen \& Monin, 2016). Strikingly, they are less strong when moral behavior is reflective of a strong identification with moral values (Conway \& Peetz, 2012). This suggests that the motivation for why individuals want to uphold their moral identity moderates licensing effects. SDT provides a stringent theoretical explanation for this moderation, as will be demonstrated in the following section.

\section{Self-determination and moral identity motivation}

SDT has been described as meta-theoretical framework that comprises several more specific mini-theories, such as Cognitive-Evaluation Theory, Organismic Integration Theory, Basic Psychological Needs Theory, and Goal Contents Theory (Ryan \& Deci, 2018). The common denominator for all these mini-theories is the idea that individuals' motivation to act can be more or less external or internal to the self. If motivation is internal the action freely emanates from the self. It reflects what a person genuinely wants to do. If motivation is external, people feel coerced into doing something 
they do not fully embrace. The prototypical example for internal motivation is the enjoyment of pursuing a pleasurable activity, such as engaging in sports or playing a musical instrument. External motivation by contrast is present when actions are instrumental for achieving standards and goals set by others.

According to Organismic Integration Theory, external and internal motivation is not binary but defines polar opposites on a continuum (e.g., Deci \& Ryan, 2012). There are other forms of motivation on this continuum that differ with regard to the degree of self-integration. Next to external motivation but somewhat more internal, is introjected motivation where external contingencies (such as the approval or disapproval of others) affect people's self-worth; maintaining this self-worth becomes an important motive for action. One step further towards internal motivation is identified motivation, where people accept the importance of a specific activity and act out of this acceptance. Finally, there is integrated motivation that occurs when identified motives become congruent with other personal needs, goals and self-ideals. As a consequence, it is not only the importance of an isolated activity, but its importance in relation to other goals that motivates action.

Note that these four types of motivation do not describe a sequence of stages, where a child proceeds from purely extrinsic to integrated motivation in a stage-like fashion. Ryan and Deci (2000) explicitly rule out that the various forms of motivation form a developmental continuum. Internal motivation can occur at any developmental period depending on the circumstances at hand. In line with this view, it has been demonstrated that even 18 months old infants spontaneously engage in helping or sharing without being asked or rewarded to do so (Warneken \& Tomasello, 2008). Thus, some 
form of internal moral motivation is evident already in infancy (Hepach, Vaish, \& Tomasello, 2013).

However, it is important to differentiate between moral behavior that emerges spontaneously without any internal struggles, on the one hand, and situations of conflicting goals, interests and desires, on the other. A child might be perfectly happy to share a bountiful resource with someone else and may be intrinsically motivated to do so because it is a pleasure to share. But what if the sharing involves personal costs? A teenager may strongly believe that cheating in an exam is unfair to others. But what if there is an equally strong desire to excel in the exam? In such situations, individuals need to be able to prioritize morality over other goals and desires, which requires a corresponding motivation to do so.

The motivation to prioritize morality over other conflicting goals and desires can derive from individuals' motivation to maintain a moral identity. As described in the previous paragraph, this motivation to maintain a moral identity can be more or less external or internal to the self. People may prioritize morality over other conflicting goals because they want to demonstrate their moral identity to others or to themselves. In this case, the motivation that derives from a person's moral identity is extrinsic or introjected. Alternatively, individuals may prioritize morality because they believe it is important and reflects the type of person they want to be. In this situation, moral identity motivation is identified or integrated. As will be demonstrated in the next section, these different forms of moral identity motivation link moral identity with moral action in systematic and meaningful, yet differential ways. Moreover, they provide a conceptual framework for describing important aspects of moral identity development. 
For the remaining sections of this paper, the distinction between internal and external moral identity motivation is pivotal. As pointed out before, these two forms of motivation are not binary but describe polar opposites on a continuum. Still, for the sake of brevity we will refer to them as two major categories of motivation as is common practise in the SDT literature (also referred to as controlled and autonomous motivation, e.g. Weinstein \& Ryan, 2010).

\section{External versus internal moral identity motivation: Links to moral action}

The distinction between external and internal moral identity motivation has not played any significant role in moral identity research to date. As Krettenauer (2011) pointed out, moral identity is often conceptualized as the centrality or importance of morality to an individual's sense of self without considering the motives for why being moral is deemed important. Yet, moral identity research has not been completely oblivious to this differentiation. The widely used Self-Importance of Moral Identity Questionnaire developed by Aquino and Reed (2002) speaks to it indirectly. This measure assesses individuals' moral identity along two dimensions, dubbed internalization and symbolization. Internalization defines moral identity inwardly as a personal striving. Symbolization, by contrast, focuses on publicly demonstrating moral behavior (e.g., I am actively involved in activities that communicate to others that I have these characteristics [of a highly moral person]). Internalization and symbolization are conceptually related to internal and external moral identity motivation. If someone expresses the desire to be a moral person this reflects internal moral identity motivation. If someone stresses the importance of demonstrating moral behavior to others it indicates external motivation. 
Yet, the two scales represent the two forms of motivation only imperfectly as the two scales confound the two forms of motivations to some extent. This limitation particularly applies to the symbolization scale as some of the items simply state the desire to express one's moral identity in actual behavior without specifying any motives for doing so. It may be that individuals seek recognition from others, which is external, or want to act in accordance with their moral ideals, which is internal. Empirically, strong correlations of .60 and higher have been reported between internalization and internal moral identity motivation, whereas symbolization is more ambiguous (Krettenauer \& Casey, 2015). It is moderately correlated with both external and internal motivation.

Against this backdrop, it is particularly noteworthy that the internalization scale repeatedly turned out to be the stronger and more reliably predictor of moral action than symbolization (Hertz \& Krettenauer, 2016; Jennings et al., 2015). Evidently, internal moral identity motivation as represented by the internalization scale is more effective in motivating moral action. This finding is in full agreement with SDT that generally stresses that internal motivation provides a stronger and more self-sustaining form of motivation as compared to external motivation (e.g., Deci \& Ryan, 2012; Ryan \& Deci, 2018). This stronger motivational impact is likely related to the emotions involved when engaging in moral actions. For instance, it has been shown that internally motivated helping behavior is experienced as more satisfying and self-rewarding than externally motivated helping behavior (Weinstein \& Ryan, 2010). In a similar vein, it was shown that internal motivation is positively correlated with authentic pride, that is positive feelings about one's moral action and the positive effect it has on others (Krettenauer \& Casey, 2015). In contradistinction, external motivation is more strongly correlated with 
hubristic pride, i.e., positive feelings derived from one's supposed moral superiority relative to others. Hubristic pride, in turn, is less strongly associated with prosocial behavior than authentic pride.

The differential impact of internal moral motivation on moral action does not only involve emotions but also cognitive mechanisms. The two mechanisms described in the previous paragraph that potentially undermine the link between moral identity and action, moral disengagement and moral licencing, are differentially associated with the two forms of moral identity motivation. Research demonstrates that strategies of moral disengagement are less effective when individuals score high on the moral identity internalization scale (Aquino, Reed, Thau, \& Freeman, 2007; Hardy, Bean, \& Olsen, 2014). Thus, a strong internal moral identity motivation makes it more difficult to effectively disengage from one's own immoral behavior. In line with this finding it was found that individuals with high internal moral identity motivation dissociate themselves less from past immoral actions (Krettenauer \& Mosleh, 2013) and are less defensive about them (Weinstein, Deci, \& Ryan, 2011). Thus, internal moral identity motivation is associated with a stronger sense of responsibility likely because moral actions in general are experienced as more self-determined.

Moral identity motivation also moderates the influence of past moral behavior on future moral actions as described in research on moral licencing. It has been demonstrated that licencing effects depend on a variety of moderating factors (Mullen \& Monin, 2016). While there is no empirical study that directly investigated the moderating role of moral identity motivation on moral licencing, licencing was found to be less strong or even turned into the opposite consistency effect when the past behavior reflects 
an underlying value the individual strongly identifies with (Conway \& Peetz, 2012).

Value identification is indicative of a strong internal moral identity motivation. Thus, internal moral identity motivation is likely less prone to licensing effects.

Of course, all this does not imply that external moral identity motivation is incapable of motivating moral action. It does so, yet in different ways. If individuals who are externally motivated believe they need to maintain their status as a valued member of their moral community by behaving morally, they likely will do so (Winterich, Aquino, Mittal, \& Swartz, 2013). This may even lead to what has been described as escalation of commitment (Schaumberg \& Wiltermuth, 2014), which occurs when individuals compete for social status gains through prosocial and cooperative behavior (see also Barclay, 2012). However, when there is no such incentive, external moral identity motivation has little influence on moral action. It some situations, it may be possible to maintain a social moral identity without acting morally. In such situations, external moral identity motivation leads to what has been described as moral hypocrisy by Batson and others (for an overview see, Batson, 2016) .

In a series of experiments, Batson and colleagues demonstrated that individuals pretend to act morally but try to avoid the costs of being moral whenever possible (Batson, Thompson, \& Chen, 2002; Batson, Thompson, Seuferling, Whitney, \& Strongman, 1999). Similarly, Dana, Weber, and Kuang, (2007) found that leaving individuals with some "wiggle room" to serve their own self-interest while maintaining the illusion of fairness behavior in a dictator game makes them share less with their partner. According to Batson (2016) individuals are primarily motivated to appear moral while avoiding the costs of actually being moral whenever possible, which explains why 
morality so often fails. While Batson's claims about the pervasiveness of hypocrisy motivation appear to be overstated (see Krettenauer, Bauer \& Sengsavang, 2019), these studies nonetheless demonstrate important limitations of an external moral identity motivation. If moral identity motivation is purely external, moral actions are driven by external contingencies and the desire to maintain one's social status as a moral person. This can lead to strategic behavior when individuals try to appear moral without acting morally.

In sum, there is considerable support for the idea that the two forms of moral identity motivation are differentially linked to moral action. Thus, moral identity has different effects on moral action depending on whether it is external or internal. The impact of external moral identity motivation is contingent on whether one's actions influence the way others view the self. Internal moral identity motivation, by contrast, leads to the desire to maintain one's self-ideal. Internal motivation provides a stronger and more reliable link between moral identity and moral action and prevents individuals from merely creating the impression of being moral while avoiding the costs of acting morally.

\section{Moral identity motivation and development}

As pointed out by Krettenauer \& Hertz (2015), a major limitation of the two leading approaches to moral identity (trait-based and socio-cognitive) is in the lack of a developmental account. From a trait-based perspective, the essence of moral identity is in stability over time, which is the opposite of developmental change. For socio-cognitive approaches, moral identity results from the repeated activation of moral self-schemas, which renders them more accessible and more influential in regulating social behavior 
(Lapsley \& Stey, 2014). The type of identity motivation that is triggered in a specific situation, may it be external or internal, is not of particular interest, nor are the factors that influence the importance of internal motivation relative to external motivation. However, since external and internal moral identity motivation are differentially linked to moral action, the question of what influences the importance of internal moral identity motivation relative to external motivation is of great significance.

One influential factor might be development. Various models of self, identity and moral development propose a general developmental trend towards higher levels of selfdetermination and self-integration. As individuals grow older, life-goals, values and ideals are increasingly experienced as self-chosen (e.g. Blasi \& Glodis, 1995; Hy \& Loevinger, 1996; Marcia, Waterman, Matteson, Archer, \& Orlofsky, 1993). Even Kohlberg's stage model of moral development suggests a decline in external and increase in internal motivation as adolescents move out of the preconventional Stages 1 and 2 and standards of individual conscience become more salient at the Stages 3-4 and 4 (Colby, Kohlberg, Gibbs, \& Lieberman, 1983). In line with these models, SDT posits an organismic trend towards higher levels of self-integration. According to SDT, it is through identification of values and goals as one's own and self-integration that internal motivation develops. It is important to note, however, that this internal motivation requires supportive developmental contexts to occur (Deci \& Ryan, 2014). Such context dependency is evident in contextual differences when goal-motivations in one area of life are highly internal (e.g., leisure activities) but may remain external in others (e.g., work). Age-related increases in internal motivation over the life-span have been documented for personal goals (Sheldon \& Kasser, 2001), for social role obligations 
(Sheldon, Kasser, Houser-Marko, Jones, \& Turban, 2005), and more recently also for moral identity motivation (Krettenauer \& Victor, 2017). Krettenauer and Victor assessed moral identity motivation using a newly developed interview procedure. Participants were first asked to choose 12-15 values or virtues from a list of 80 to define a highly moral person from their personal point of view. All values on this list of 80 had been identified as prototypical descriptors of a highly moral person in previous research (for details see Krettenauer, Murua, \& Jia, 2016). Participants were then asked to rate the selfimportance of these values by sorting them on a diagram with 'extremely important to me' at the core and 'unimportant to me' are at the periphery. They were asked to do this independently for three different contexts, namely family, work or school (depending on enrollment status) and community/the larger society. For those attributes that were put in the center of each diagram, interviewees were finally asked why these qualities were extremely important to them. Responses to this question were coded as external, internal or as relationship-oriented. External motives refer to self-interest or social reputation. Internal motives, by contrast, refer to self- and relationship ideals and/or one's desire to be a role model to others. Relationship-oriented motives refer to the good relationship one wants to keep with others and are neither clearly external nor internal. They were therefore kept as a separate category.

In a sample of 25214 to 65 year old Canadian participants it was found that external motivation decreased from adolescence to adulthood, whereas relationshiporiented motives did not evidence much age-related change (see Figure 1). Internal motivation, by contrast, increased from adolescence to adulthood. Moral identity motivation was not only related to age but to context, as well. In the work/school context 
external moral identity motivation was clearly dominant, whereas in the family and community context all three types of moral identity motivation were on par (see Figure 1). While this finding documents substantial context-dependency of moral identity in terms of mean level differences, moral identity motivations in the three contexts were nonetheless significantly correlated, with a median correlation of $r=.31, \mathrm{p}<.05$.

Similar trends can be found in earlier developmental periods. In a follow up study with a sample of 9 to 15 year olds we used a similar method with slight modifications (for details see Sengsavang, 2018). In this study, we presented students a list of 13 preselected moral values that are known to be important for defining a highly moral person particularly in this younger age period such as being honest, trustworthy, genuine, non-judgmental, responsible, and selfless. Participants were asked to rate the selfimportance of these values by sorting them on the same diagram with 'extremely important to me' at the core and 'unimportant to me' are at the periphery. They were asked to do this independently for three contexts, namely family, friends and school. The motives for why these values were extremely important were coded with a slightly revised coding manual that is more closely aligned with the organismic integration model as proposed by SDT. There were external responses, in which respondents referred to external standards and rules or negative consequences to the self (e.g., my parents want me to be honest; if I lie to others, they will lie to me too). There were introjected responses, referring to one's reputation or to consequences for relationships (e.g., I want my teacher to think of me as a reliable student, there won't be a trusting relationship anymore). There were identified reasons, where respondents refer to negative consequence of immoral actions for others and/or the golden rule. Finally, there were 
integrated responses, in which participants explained the important of these moral qualities by referring to their own self- or relationship ideals. For three out of four of these motivational categories we found significant age-related differences in line with the idea that moral identity motivation becomes more internal with age. External and introjected motivation decreased from late childhood to mid adolescents whereas identified and integrated motivation increased (see Figure 2). Again, as in the first study, there was considerable context dependency, with external moral identity motivation being most prevalent in the context of school and introjected motivation being most common in the context of peers (see Figure 2).

Taken together these findings clearly support the notion that internal moral identity motivation increases with age while external motivation decreases. Developmental change appears to be most pronounced in adolescence and early adulthood and reaches a plateau around the age of 25 years. This age period is commonly perceived as crucial for moral identity development, although later developmental change still can occur (see Krettenauer \& Hertz, 2015; Krettenauer, Murua, \& Jia, 2016). At the same time, context differences point to the importance of contextual support for internal moral identity motivation to occur.

\section{Conclusion and outlook}

As described at the beginning, research on moral identity has been dominated by two major approaches, trait-based and socio-cognitive accounts. These two accounts of moral identity differ with regard to their theoretical underpinnings. At the same time, they lead to contrary predictions in regards of the context- and situation-dependency of moral identity. While trait-based approaches consider moral identity a stable personality 
characteristic that is largely context independent, socio-cognitive approaches deal with moral identity as a highly malleable and fluctuating self-attribute. From a socio-cognitive perspective, moral identity is one particular self-schema among many others that needs to be activated in a given situation to exert any influence. The view presented in this paper takes a middle ground between these two extremes. It allows for some contextdependency without assuming that a person's identity falls apart into bits and pieces. From a self-determination theory perspective, individuals strive for self-integration and consequently demonstrate some coherence in moral identity across contexts (see also Nucci, 2018).

The notion of an integration of morality and self has been at center stage for research on moral identity for a long time. According to this idea, it is the gradual integration of self and morality in the course of development that gives rise to a moral identity. Researchers employed different concepts as to what this integration of self and morality exactly entails. Blasi and Glodis (1995), for instance, described different identity modes, from defining one's identity through observable characteristics to managing and shaping one's identity by expressing one's core values and approximating one's ideals. Colby and Damon (1992) elaborated on the notion of an integration of self and morality on the basis of a qualitative study of moral exemplars. They found that moral exemplars expressed a marked unity between self and morality such that their own personal interests and desires were identical with what they perceived as morally desirable. Frimer and Walker (2009) further corroborate and expanded Colby and Damon's ideas. According to, Frimer and Walker's reconciliation model of moral identity development, human motivation entails a fundamental duality between agency and communion. Individuals 
normally work towards either achieving their own goals or advancing those of others. This duality is overcome either by prioritizing one motivational system over the other or by reconciling the two. Reconciliation is the integration of agency and communion such that agential desires are fulfilled through the pursuit of communal concerns. According to Walker (2014), reconciliation of agency and communion is the hallmark of moral maturity.

The perspective taken in the present paper fully resonates with the notion that moral identity development is in the integration of self and morality. Yet, it does not assume that there are two broad psychological systems "morality" and "self" that become gradually integrated in the course of development. Rather it assumes that there is a specific goal of moral identity maintenance that becomes more internally motivating with development. At one particular point, however, the perspective taken in this paper clearly deviates from the models formulated by Blasi, Colby, Damon and Walker. All of these models assume that the developmental period of childhood is void of moral identity. This assumption is questionable on various conceptual and empirical grounds (see Krettenauer, 2014; 2018). According to the view promoted in this paper, children already possess a moral identity long before a fully internalized and integrated moral identity emerges in the course of the development. This moral identity is externally defined by the desire to meet the expectations of one's moral community. Empirical research demonstrates that children as young as 5 years of age try to manage their social reputation in their peer group by abstaining from antisocial behaviors such as stealing or cheating and by acting prosocially (Engelmann \& Rapp, 2018). For example, children share more when they are watched by others even if the recipient is absent and the 
observer is an unaffected peer (Engelmann, Herrmann, \& Tomasello, 2012). This effect is stronger, when the observer is from the child's own in-group. These active attempts to maintain one's status in a group by acting morally are an important foundation for the development of an internally motivated moral identity as it emerges at a later point in development. ${ }^{1}$ An important crossroad along this developmental pathway occurs around the age of 8 years when children start to realize that they can strategically manage their social reputation by appearing moral to others without acting morally. If moral identity motivation has remained largely external up to this point in development, moral hypocrisy as defined by Batson (2016) may follow.

A major outcome of this paper, thus, is in the notion that moral identity comes as a goal of moral action. Individuals act morally in order to uphold their moral identity. However, they do so for reasons, which are more or less external and internal to the self. External and internal moral identity motivations are differentially linked to moral actions. Internal moral identity motivation gains importance in the course of development and likely dominates external moral identity motivation at later points in development. These claims raise many questions that need to be addressed by future research. For example, how does external moral identity motivation transform into internal moral identity motivations? What are the exact mechanisms? Does the reverse process occur, as well? Do both forms of moral identity motivation coexist in one and the same person? As SDT

\footnotetext{
1 It is important to note that the dominance of an external moral identity motivation at younger ages does not preclude the existence of other forms of intrinsic moral motivation in younger children. As argued in Krettenauer (2014; 2018) young children spontaneously engage in prosocial acts of helping, sharing and caring and are intrinsically motivated to do so. However, this internal motivation is tied to singular actions and not related to children's self-view or moral identity.
} 
maintains, some aspects of a person's moral identity, particularly those that are more congruent with the basis needs for relatedness, competence and autonomy may be more internally motivating than others (see Avanitis, this issue; Besser, this issue). As a consequence, individuals' moral identity may blend external and internal motivations. It is evident that the two main approaches to moral identity, trait-based and socio-cognitive accounts, have very little to offer for addressing these questions. In view of this conclusion, it is fair to say that the SDT-perspective promoted in this paper offers a promising avenue for new research that significantly broadens the scope of studies on moral identity and its development. 


\section{References}

Aquino, K., \& Reed, A. (2002). The self-importance of moral identity. Journal of Personality and Social Psychology, 83, 1423-1440.

Aquino, K., Reed, A., Thau, S., \& Freeman, D. (2007). A grotesque and dark beauty: How moral identity and mechanisms of moral disengagement influence cognitive and emotional reactions to war. Journal of Experimental Social Psychology, 43(3), 385-392. http://doi.org/10.1016/j.jesp.2006.05.013

Austin, J. T., \& Vancouver, J. B. (1996). Goal constructs in psychology: Structure, process, and content. Psychological Bulletin, 120(3), 338-375. http://doi.org/10.1037/0033-2909.120.3.338

Bandura, A. (2016). Moral disengagment. New York: Worth Publishers.

Barclay, P. (2012). Harnessing the power of reputation: strengths and limits for promoting cooperative behaviours. Evolutionary Psychology, 10(5), 868-883.

Batson, C. D. (2016). What's wrong with morality? New York: Oxford University Press.

Batson, C. D., Thompson, E. R., \& Chen, H. (2002). Moral hypocrisy: addressing some alternatives. Journal of Personality and Social Psychology, 83(2), 330-339. http://doi.org/10.1037/0022-3514.83.2.330

Batson, C. D., Thompson, E. R., Seuferling, G., Whitney, H., \& Strongman, J. A. (1999). Moral hypocrisy: appearing moral to oneself without being so. Journal of Personality and Social Psychology, 77(3), 525-537. http://doi.org/10.1037/00223514.77.3.525

Blanken, I., Van de Ven, N., \& Zeelenberg, M. (2015). A Meta-Analytic Review of Moral Licensing. Personality and Social Psychology Bulletin, 41(4), 540-558. 
http://doi.org/10.1177/0146167215572134

Blasi, A. (1983). Moral cognition and moral action: A theoretical perspective. Developmental Review, 3, 178-210.

Blasi, A. (1984). Moral identity: Its role in moral functioning. In W. M. Kurtines \& J. L. Gewirtz (Eds.), Morality, moral behavior, and moral development (pp. 128-139). New York: Wiley.

Blasi, A. (2005). What should count as moral behavior? The nature of "early morality" in children's development. In W. Edelstein \& G. Nunner-Winkler (Eds.), Morality in context (pp. 119-140). Amsterdam: Elsevier.

Blasi, A., \& Glodis, K. (1995). The development of identity. A critical analysis from the perspective of the self as subject. Developmental Review, 15, 404-433.

Colby, A., \& Damon, W. (1992). Some do care. Contemporary lives of moral commitment. New York: Free Press.

Colby, A., Kohlberg, L., Gibbs, J., \& Lieberman, M. (1983). A longitudinal study of moral judgment, Monographs(48, (1-2, Serial No. 200)).

Conway, P., \& Peetz, J. (2012). When Does Feeling Moral Actually Make You a Better Person? Conceptual Abstraction Moderates Whether Past Moral Deeds Motivate Consistency or Compensatory Behavior. Personality and Social Psychology Bulletin, 38(7), 907-919. http://doi.org/10.1177/0146167212442394

Dana, J., Weber, R. a., \& Kuang, J. X. (2007). Exploiting moral wiggle room: Experiments demonstrating an illusory preference for fairness. Economic Theory, 33(1), 67-80. http://doi.org/10.1007/s00199-006-0153-z

Deci, E. L., \& Ryan, R. M. (2012). Motivation, personality, and development within 
embedded social contexts: An overview of self-determination theory. In R. M. Ryan (Ed.), The Oxford Handbook of Human Motivation (pp. 85-107). Oxford: Oxford University Press.

Deci, E. L., \& Ryan, R. M. (2014). The importance of autonomy for development and well-being. In B. W. Sokol, F. Grouzet, \& U. Müller (Eds.), Self-regulation and autonomy (pp. 19-46). New York: Cambridge University Press.

Ellemers, N., Pagliaro, S., \& Barreto, M. (2013). Morality and behavioural regulation in groups: A social identity approach. European Review of Social Psychology, 24(1), 160-193. http://doi.org/10.1080/10463283.2013.841490

Engelmann, J. M., Herrmann, E., \& Tomasello, M. (2012). Five-Year Olds, but Not Chimpanzees, Attempt to Manage Their Reputations. PLoS ONE, 7(10). http://doi.org/10.1371/journal.pone.0048433

Engelmann, J. M., \& Rapp, D. J. (2018). The influence of reputational concerns on children's prosociality. Current Opinion in Psychology, 20, 92-95. http://doi.org/10.1016/j.copsyc.2017.08.024

Frimer, J. A., \& Walker, L. J. (2009). Reconciling the self and morality: An empirical model of moral centrality development. Developmental Psychology, 45, 1669-1681. Hardy, S. (2006). Identity, reasoning, and emotion: An empirical comparison of three sources of moral motivation. Motivation and Emotion, 30(3), 205-213. http://doi.org/10.1007/s11031-006-9034-9

Hardy, S., Bean, D., \& Olsen, J. (2014). Moral Identity and Adolescent Prosocial and Antisocial Behaviors: Interactions with Moral Disengagement and Self-regulation. Journal of Youth and Adolescence, 1542-1554. http://doi.org/10.1007/s10964-014- 
0172-1

Hardy, S., \& Carlo, G. (2005). Identity as a source of moral motivation. Human Development, 48, 232-256.

Hardy, S., \& Carlo, G. (2011). Moral Identity: What is it, how does it develop, and is it linked to moral action? Child Development Perspectives, 5, 212-218.

Hepach, R., Vaish, A., \& Tomasello, M. (2013). A new look at children's prosocial motivation. Infancy, 18(1), 67-90. http://doi.org/10.1111/j.1532-7078.2012.00130.x

Hertz, S. G. S. G., \& Krettenauer, T. (2016). Does moral identity effectively predict moral behavior?: A meta-analysis. General Review of Psychology, 20(2), 129-140. http://doi.org/http://dx.doi.org/10.1037/gpr0000062

Hy, L. X., \& Loevinger, J. (1996). Measuring ego development. Mahwah, NJ: Erlbaum. Jennings, P. L., Mitchell, M. S., \& Hannah, S. T. (2015). The moral self: A review and integration of the literature. Journal of Organizational Behavior, 104-168. http://doi.org/10.1002/job.1919

Krettenauer, T. (2011). The dual moral self: moral centrality and internal moral motivation. The Journal of Genetic Psychology, 172(4), 309-28. http://doi.org/10.1080/00221325.2010.538451

Krettenauer, T. (2014). Revisiting the moral self construct: Developmental perspectives on moral selfhood. In B. W. Sokol, U. Müller, \& F. Grouzet (Eds.), Self-regulation and autonomy (pp. 115-140). Cambridge: Cambridge University Press.

Krettenauer, T. (2018). Children's moral self as a precursor of moral identity development. In C. C. Helwig (Ed.), New Perspectives on Moral Development (pp. 73-87). New York: Routledge. 
Krettenauer, T., \& Casey, V. (2015). Moral identity development and positive moral emotions: Differences involving authentic and hubristic pride. Identity, 15(3), 173187. http://doi.org/10.1080/15283488.2015.1023441

Krettenauer, T., \& Hertz, S. (2015). What develops in moral identities? A critical review. Human Development, 58(3), 137-153. http://doi.org/10.1159/000433502

Krettenauer, T., \& Mosleh, M. (2013). Remembering Your (Im)Moral Past: Autobiographical Reasoning and Moral Identity Development. Identity, 13(2), 140158. http://doi.org/10.1080/15283488.2013.776497

Krettenauer, T., Murua, L. A., \& Jia, F. (2016). Age-related differences in moral identity across adulthood. Developmental Psychology, 52(6), 972-984. http://doi.org/http://dx.doi.org/10.1037/dev0000127

Krettenauer, T., \& Victor, R. (2017). Why be moral? Moral identity motivation and age. Developmental Psychology, 53(8), 1589-1596. http://doi.org/10.1037/dev0000353

Lapsley, D. K., \& Stey, P. C. (2014). Moral self-identity as the aim of education. In L. Nucci, D. Narvaez, \& T. Krettenauer (Eds.), Handbook of Moral and Character Education (pp. 84-100). New York: Routledge.

Marcia, J. E., Waterman, A. S., Matteson, D. R., Archer, S. L., \& Orlofsky, J. L. (1993). Ego identity. A handbook for psychological research. New York: Springer.

Mazar, N., Amir, O., \& Ariely, D. (2008). The dishonesty of honest people. Journal of Marketing Research, XLV(December), 633-644.

McAdams, D. P. (1993). The stories we live by. New York: Guilford Press. McAdams, D. P. (2015). The art and science of personality development. New York: Guilford Press. 
Mullen, E., \& Monin, B. (2016). Consistency versus Licensing Effects of Past Moral Behavior. Annual Review of Psychology, 67, 363-385. http://doi.org/10.1146/annurev-psych-010213-115120

Nucci, L. (2004). The promise and limitations of the moral self construct. In C. Lightfoot, C. E. Lalonde, \& M. J. Chandler (Eds.), Changing conceptions of psychological life (pp. 49-70). Mahwah, NJ: Erlbaum.

Nucci, L. (2018). Character: A Developmental System. Child Development Perspectives, O(0), 1-6. http://doi.org/10.1111/cdep.12313

Pasupathi, M., \& Wainryb, C. (2010). Developing Moral Agency through Narrative. Human Development, 53(2), 55-80. http://doi.org/10.1159/000288208

Ryan, R. M., \& Deci, E. L. (2000). Intrinsic and extrinsic motivations: Classic definitions and new directions. Contemporary Educational Psychology, 25, 54-67.

Ryan, R. M., \& Deci, E. L. (2008). Self-Determination Theory and the role of basic psychological needs in personality and the organization of behavior. In P. John, R. W. Robins, \& L. A. Pervin (Eds.), Handbook of personality (pp. 654-678). New York: Guilford.

Ryan, R. M., \& Deci, E. L. (2018). Self-determination theory. New York: Guilford Press. Sachdeva, S., Iliev, R., \& Medin, D. L. (2009). Sinning saints and saintly sinners: the paradox of moral self-regulation. Psychological Science, 20(4), 523-8. http://doi.org/10.1111/j.1467-9280.2009.02326.x

Schaumberg, R. L., \& Wiltermuth, S. S. (2014). Desire for a positive moral self-regard exacerbates escalation of commitment to initiatives with prosocial aims. Organizational Behavior and Human Decision Processes, 123(2), 110-123. 
http://doi.org/10.1016/j.obhdp.2013.10.012

Sengsavang, S. (2018). Moral identity development across middle childhood and adolescence. Unpublished doctoral disseration. Waterloo, Ontario: Wilfrid Laurier University.

Sheldon, K. M., \& Kasser, T. (2001). Getting older, getting better? Personal strivings and psychological maturity across the life span. Developmental Psychology, 37, 491501.

Sheldon, K. M., Kasser, T., Houser-Marko, L., Jones, T., \& Turban, D. (2005). Doing one's duty: Chronological age, felt autonomy, and subjective well-being. European Journal of Personality, 19(2), 97-115. http://doi.org/10.1002/per.535

Soenens, B., \& Vansteenkiste, M. (2011). When is identity congruent with the self? A self-determination theory perspective. In S. J. Schwartz, K. Luyckx, \& V. L. Vignoles (Eds.), Handbook of identity theory and research (pp. 381-402). New York, NY: Springer.

Stets, J. E., \& Carter, M. J. (2012). A theory of the self for the sociology of morality. American Sociological Revieew, 77(120-140).

Walker, L. J. (2014). Moral personality, motivation, and identity. In M. Killen \& J. G. Smetana (Eds.), Handbook of moral development (pp. 497-519). New York: Psychology Press.

Warneken, F., \& Tomasello, M. (2008). Extrinsic rewards undermine altruistic tendencies in 20-month-olds. Developmental Psychology, 44, 1785-1788.

Weinstein, N., Deci, E. L., \& Ryan, R. M. (2011). Motivational determinants of integrating positive and negative past identities. Journal of Personality and Social 
Psychology, 100(3), 527-544. http://doi.org/10.1037/a0022150

Weinstein, N., \& Ryan, R. M. (2010). When helping helps: Autonomous motivation for prosocial behavior and its influence on well-being for the helper and recipient. Journal of Personality and Social Psychology, 98(2), 222-244. http://doi.org/10.1037/a0016984

Winterich, K. P., Aquino, K., Mittal, V., \& Swartz, R. (2013). When moral identity symbolization motivates prosocial behavior: The role of recognition and moral identity internalization. Journal of Applied Psychology, 98(5), 759-770. http://doi.org/10.1037/a0033177 

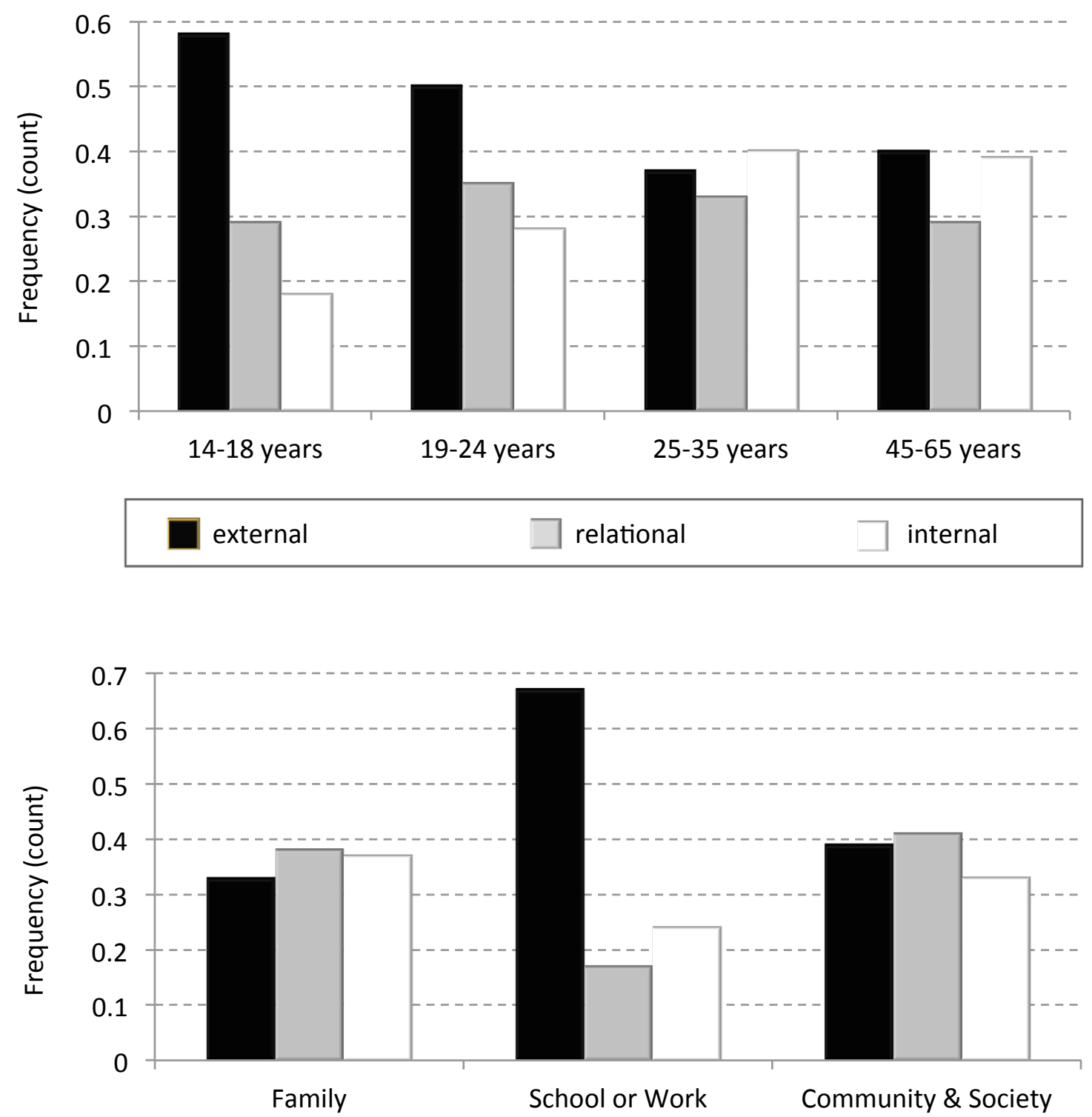

Figure 1. External and internal moral motivation by age and context (Study I, $N=256$ ) 

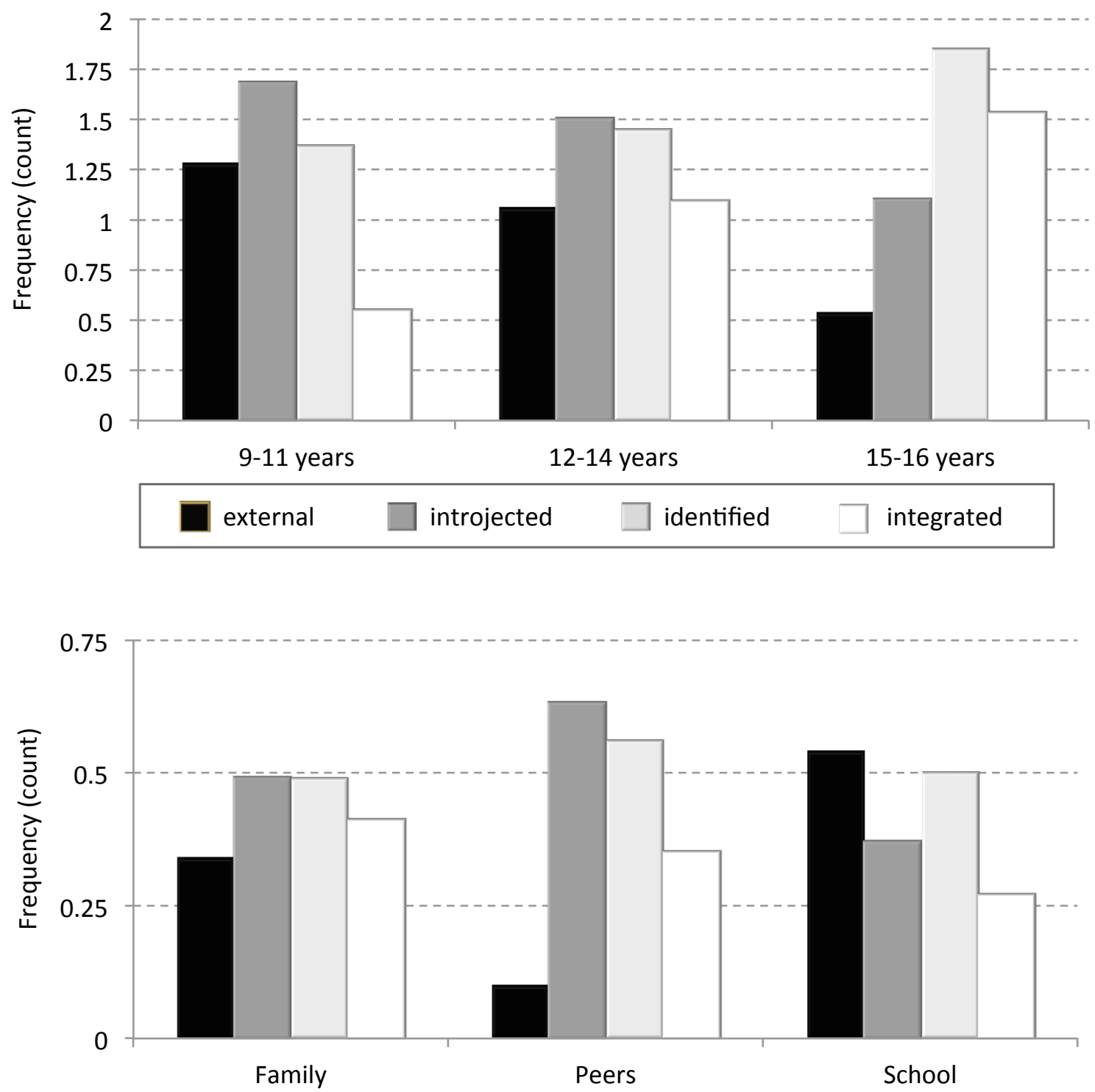

Figure 2. External, introjected, identified and integrated moral identity motivation by age and context (Study II; $N=186$ ) 